\title{
INDICADORES SOCIO-LABORALES Y VIABILIDAD SECTORIAL DE LA REDUCCIÓN DEL TIEMPO DE TRABAJO EN GIPUZKOA ${ }^{1}$
}

\author{
Verónica Castrillón Serna \\ Jose MARI Zendoia SAINZ \\ Jon BERNAT Zubiri ReY \\ Departamento de Economía Aplicada I \\ Euskal Herriko Unibertsitatea / Universidad del País Vasco (UPV/EHU)
}

DOI: $10.1387 /$ lan-harremanak.16566

\section{ABSTRACT}

El objeto de este artículo es analizar la evolución seguida por la distribución funcional de la renta (o distribución de salarios y beneficios) y los costes laborales unitarios en Gipuzkoa a lo largo del periodo 1995-2012, de cara a justificar la viabilidad de una reducción del tiempo de trabajo. Con este fin vamos a presentar algunos indicadores socio-laborales, incluyendo en nuestro análisis tanto el último ciclo expansivo de la economía (1995-2007), como los cinco primeros años de la recesión iniciada en 2008. Nuestro estudio culmina con una desagregación por sectores económicos, lo que permite esclarecer aquellos que presentan un comportamiento más favorable al impulso de politicas de empleo en favor de la reducción del tiempo de trabajo.

${ }^{1}$ La autoría de este artículo está indicada por orden alfabético, justificada en el trabajo equitativamente compartido de análisis del reparto del tiempo de trabajo, en el marco del Proyecto de Investigación «Reparto del empleo y del tiempo de trabajo: efectos en la fiscalidad y tratamiento jurídico», financiado por el Departamento de Innovación de la Diputación Foral de Gipuzkoa, a ejecutar entre el 22-12-2014 y el 30-10-2015. 
Palabras clave: distribución de la renta, costes laborales, reducción del tiempo de trabajo, Gipuzkoa, sectores económicos.

The aim of this paper is to analyse the evolution of the functional distribution of income (or distribution of salaries and profits) and unit labor costs in Gipuzkoa throughout the period 1995-2012, in order to justify the feasibility of a reduction in working time. For this purpose, we will introduce some socio-laboral indicators, including the analysis of both the last expansionary cycle of the economy (1995-2007) and the first five years of the recession that began in 2008. Our study concludes with a desegregation by economic sectors, which allows us to identify those which will respond most favourably to a boost in employment policies geared towards a reduction in working hours.

Keywords: income distribution, labour costs, working-time reduction, Gipuzkoa, economic sectors.

Artikulu honen xedea da $1995-2012$ urteen artean errentaren banaketa funtzionalak eta lan-kostu unitarioek Gipuzkuan izandako garapena aztertzea, lanaldi murrizketaren bideragarritasuna justifikatu ahal izateko. Helburu horrekin, adierazle soziolaboral batzuk aurkeztuko ditugu, horretarako azken ziklo hedakorra (1995-2017) eta 2008an hasitako gainbeheraren lehen bost urteak barneratu ditugu. Gure lana amaituko dugu sektore ekonomikoen bereizketarekin, horrek lanaldi murrizketaren aldeko enplegu politIken sustapenaren aldeko sektoreak zeintzuk diren argitzen laguntzen digulako.

Hitz gakoak: errentaren banaketa, lan-kostuak, lanaldi murrizketa, Gipuzkoa, sektore ekonomikoak. 


\section{Introducción}

En este artículo vamos a realizar una presentación agregada de los indicadores anteriormente expuestos, con la intención de delimitar la estructura sociolaboral de la economía gipuzkoana y la viabilidad de llevar a cabo políticas de Reducción del Tiempo de Trabajo (en adelante RTT) a escala sectorial. Empezaremos con una presentación de indicadores para el total de las relaciones laborales remuneradas en Gipuzkoa en su conjunto — asalariadas, auto-empleadas, empresarias y otros estatus de menor incidencia-, dando paso a un presentación de los 16 sectores estudiados, que ocupan al 80,8\% de las personas asalariadas en el herrialde.

Para esta síntesis de datos a nivel sectorial, hemos elegido los siguientes indicadores:

— Cantidad de personas ocupadas (todos los estatus) y en particular de las asalariadas, que son las que necesitamos identificar para ver el volumen y potencial generador de empleo de una política de RTT, dando lugar a la tasa de salarización (asalariadas / ocupadas), que identifica la composición orgánica del trabajo a nivel sectorial.

- La cantidad de puestos de trabajo asalariado, que da lugar a hablar de tasas de completitud - puestos asalariados en Equivalente Tiempo Completo (ETC) dividido entre cantidad total de puestos asalariados-, indicador inverso al grado de parcialidad de los puestos de trabajo en el sector.

—El Valor Añadido Bruto (en adelante, VAB) del sector -o PIB a coste de los factores-, la productividad horaria de la población ocupada (asalariadas + empresarias + auto - empleadas, mayormente) y la remuneración horaria de las asalariadas, ambas nominales, es decir a precios corrientes de los ańos observados. La relación de estos dos indicadores nos da lugar a los Costes Laborales Unitarios (en adelante, CLU), siendo este último el factor más importante en las políticas laborales a nivel de empresa, sector o de aplicación global.

Por último, hemos comparado las horas anuales medias de una persona asalariada a tiempo completo y las horas anuales medias de las asalariadas reales -las de tiempo completa y tiempo parcial-. 
La observación de estos indicadores en cada sector, nos va a permitir clasificar aquellos en los que las políticas de RTT es más o menos factible, usando la siguiente mecánica para determinar el grado de viabilidad sectorial. Alonso y Pérez (1996) nos recuerdan que:

«Hay que reflexionar sobre las cuestiones relacionadas con la productividad, los salarios y la utilización de los equipos productivos. También esta la influencia de la RTT sobre los comportamientos de actividad y sobre el equilibrio entre oferta y demanda de trabajo, y de las diferentes maneras en que los distintos sectores e incluso ramas de actividad pueden absorber la reducción de la jornada.»

Por tanto, el aumento de efectivos asalariados y la tasa de salarización de un sector se consideran positivos para la RTT. Igualmente, la alta tasa de completitud muestra baja parcialidad en el empleo y, por tanto, la posibilidad de una política de RTT, ya que no hace falta establecer como prioridad el tránsito a jornada completa de los contratados a tiempo parcial — principalmente forzado- (Berbel, 2015). En cualquier caso este indicador es de importancia menor, ya que también en sectores con alta parcialidad se puede establecer una RTT que implique el paso a jornadas completas más cortas para el conjunto de personas empleadas.

En el siguiente bloque de indicadores empezamos con la evolución positiva del VAB en los últimos años, crucial en la hipótesis de políticas de RTT cuyos costos sean capaces de asumir — total o parcialmente- las propias empresas. El costo de esta financiación a cargo de las empresas se justifica tanto por los aumentos de productividad acumulados, por encima de los aumentos de las remuneraciones, como "por los aumentos de productividad consecutivos a la RTT» (Riechmann y Recio, 1997: 81). A efectos agregados, la evolución de los Costes Laborales Unitarios (en adelante CLU) reales — productividad por hora ocupada/remuneración horaria por hora asalariada - son el factor clave en esta composición sectorial, siendo las políticas de RTT más viables dónde estos son bajos o evolucionan a la baja en los últimos años.

Por último, las horas anuales medias - tanto para las asalariadas a tiempo completo como para el conjunto de personas asalariadas - nos indican la posición relativa de cada sector en relación al conjunto de la economía gipuzkoana, siendo evidente la mayor necesidad y viabilidad de RTT en aquellos sectores en los que más horas anuales se trabaja. A continuación veremos este conjunto de indicadores para el conjunto de Gipuzkoa y para los principales 16 sectores.

\section{Evolución desde 1995 e impacto de los primeros años de ajuste (2008-2012)}

El conjunto de personas ocupadas en la economía y el empleo asalariado ha sufrido en Gipuzkoa un notable retroceso en los últimos ańos, a diferencia del 
periodo desde 1995 hasta 2008, en el cuál se habían incrementado en más de 97.000 personas el total de asalariadas en el herrialde. De las 342.549 personas ocupadas y las 297.813 asalariadas que observamos en 2008, podemos constatar una notable bajada, hasta 314.741 y 274.523 en 2012, respectivamente. Esta caída de más de 23.000 personas asalariadas en los primeros 5 años de ajuste contra la clase trabajadora, nos da muestra de la vía escogida por las economías capitalistas del Sur de Europa para paliar la crisis (Álvarez-Peralta et al., 2014) relación a la reducción del tiempo de trabajo, siendo unas personas (mayormente) obligadas a trabajar más horas (Durán, 2015) mientras otras son relegadas a un paro cada vez más cronificado (aumento de paro y del paro de larga duración).

En el periodo anterior entre 1995 y 2008, reculó la parte de personas autoempleadas o empresarias sobre el total de las dadas de alta en las empresas. Como consecuencia de esta evolución, la tasa de salarización subió en 4 puntos, hasta el $87 \%$ de la población ocupada. Esta proporción permanece estable en los cinco primeros años de crisis y ajuste contra la clase trabajadora.

Similar evolución se observa en ambos periodos para la cantidad de puestos de trabajo asalariado, mostrando estos una tasa de completitud -asalariados en E.T.C./total de puestos asalariados- que recula en los últimos cinco años de nuestra observación, mostrando un aumento de la parcialidad del empleo ya anteriormente estudiada.

Tabla 1

Indicadores sociolaborales 1995-2012. Total Gipuzkoa

\begin{tabular}{|c|c|c|c|c|c|c|c|}
\hline Datos de síntesis & 1995 & 2007 & 2008 & 2009 & 2010 & 2011 & 2012 \\
\hline Personas ocupadas & 242.393 & 340.312 & 342.549 & 330.391 & 326.576 & 323.306 & 314.741 \\
\hline Personas asalariadas & 200.649 & 296.012 & 297.813 & 288.393 & 283.988 & 281.869 & 274.523 \\
\hline$\%$ asalariadas/empleadas totales & $83 \%$ & $87 \%$ & $87 \%$ & $87 \%$ & $87 \%$ & $87 \%$ & $87 \%$ \\
\hline Puestos de trabajo asalariado & 208.318 & 307.206 & 308.976 & 299.932 & 296.013 & 294.191 & 287.051 \\
\hline T. completitud asalariadas* & $92,1 \%$ & $92,0 \%$ & $91,8 \%$ & $91,1 \%$ & $90,7 \%$ & $90,9 \%$ & $90,7 \%$ \\
\hline VAB Total (miles $€$ ) & 9.883 .125 & 22.510 .514 & 22.916 .688 & 21.530 .381 & 22.224 .113 & 22.277 .214 & 22.011 .708 \\
\hline Productividad horaria población ocupada & $23,8 €$ & $39,4 €$ & $40,1 €$ & $39,5 €$ & $41,2 €$ & $42,2 €$ & $43,2 €$ \\
\hline Remuneración por hora asalariada & $14,0 €$ & $21,5 €$ & $22,6 €$ & $23,3 €$ & $24,3 €$ & $24,7 €$ & $24,6 €$ \\
\hline Costes laborales unitarios reales & $59 \%$ & $54 \%$ & $57 \%$ & $59 \%$ & $59 \%$ & $59 \%$ & $57 \%$ \\
\hline Horas anuales asalariadas tiempo completo & 1.721 & 1.685 & 1.687 & 1.679 & 1.681 & 1.665 & 1.667 \\
\hline Horas anuales asalariado reales & 1.646 & 1.610 & 1.607 & 1.591 & 1.589 & 1.579 & 1.581 \\
\hline \multicolumn{6}{|l|}{ * T.completitud=Puestos E.T.C./Puestos total. } & \multicolumn{2}{|c|}{ Contratos iniciales 2014} \\
\hline \multirow{2}{*}{\multicolumn{6}{|c|}{ Fuente: EUSTAT. }} & Hombres & 99.389 \\
\hline & & & & & & Mujeres & 117.928 \\
\hline
\end{tabular}

Fuente: SEPE. 
El Producto Interior Bruto (PIB) gipuzkoano - a precios corrientes- se incrementa notablemente desde 1995. Esta tendencia cambia entre 2007 y 2012, dándose ligeros retrocesos según los ciclos de ajuste del crecimiento y el empleo, siendo 2009 y 2012 los años de mayores caídas en el empleo y el PIB.

Mientras la productividad de la población ocupada y la remuneración por hora asalariada —ambas también a precios corrientes - evolucionan como se indica en la tabla precedente, podemos observar que la tendencia a la baja de los Costes Laborales Unitarios (en adelante, CLU) no se acompana de una reducción sustancial de la jornada anual media de las personas asalariadas ${ }^{2}$.

Pasemos a declinar estos indicadores por sectores, analizando las principales características de estructura y la tendencia observada en los últimos 20 ańos en los 16 sectores estudiados, que ocupan, como decíamos, al 80,8\% de las personas asalariadas en Gipuzkoa.

Tabla 2

Indicadores sociolaborales. Agricultura, ganadería y pesca

\begin{tabular}{|c|c|c|c|c|c|c|c|}
\hline Datos de síntesis & 1995 & 2007 & 2008 & 2009 & 2010 & 2011 & 2012 \\
\hline Personas ocupadas & 7.609 & 6.421 & 6.351 & 5.918 & 6.567 & 6.433 & 6.034 \\
\hline Personas asalariadas & 3.204 & 2.389 & 2.399 & 2.228 & 2.161 & 2.205 & 2.088 \\
\hline$\%$ asalariadas/empleadas del sector & $42 \%$ & $37 \%$ & $38 \%$ & $38 \%$ & $33 \%$ & $34 \%$ & $35 \%$ \\
\hline Puestos de trabajo asalariado & 3.694 & 2.754 & 2.766 & 2.569 & 2.492 & 2.438 & 2.297 \\
\hline T. completitud asalariadas $(*)$ & $68,5 \%$ & $68,5 \%$ & $68,5 \%$ & $68,5 \%$ & $68,5 \%$ & $68,5 \%$ & $68,8 \%$ \\
\hline VAB sectorial (miles $€$ ) & 136.043 & 137.858 & 117.863 & 108.792 & 117.309 & 113.449 & 140.205 \\
\hline Productividad horaria población ocupada & $10,7 €$ & $13,6 €$ & $11,9 €$ & $11,6 €$ & $11,4 €$ & $10,8 €$ & $14,7 €$ \\
\hline Remuneración por hora asalariada & $13,8 €$ & $12,9 €$ & $12,0 €$ & $11,0 €$ & $13,4 €$ & $12,3 €$ & $13,0 €$ \\
\hline Costes laborales unitarios reales & $129 \%$ & $95 \%$ & $101 \%$ & $95 \%$ & $118 \%$ & $114 \%$ & $89 \%$ \\
\hline Horas anuales asalariados t. completo & 1.266 & 1.878 & 1.780 & 1.820 & 1.800 & 1.857 & 1.892 \\
\hline Horas anuales por asalariado reales & 1.000 & 1.483 & 1.406 & 1.438 & 1.422 & 1.407 & 1.433 \\
\hline \multicolumn{5}{|c|}{${ }^{*} \mathrm{~T}$. completitud $=$ Puestos E.T.C./Puestos total. } & \multicolumn{3}{|c|}{ Contratos iniciales 2014} \\
\hline \multirow{2}{*}{\multicolumn{5}{|c|}{ Fuente: EUSTAT. }} & \multirow{2}{*}{\multicolumn{2}{|c|}{$\begin{array}{l}\text { Hombres } \\
\text { Mujeres }\end{array}$}} & 1.368 \\
\hline & & & & & & & 154 \\
\hline
\end{tabular}

Fuente: SEPE.

2 Para el caso de Gipuzkoa se han calculado los CLU teniendo en cuenta el PIB a precios de mercado (incluyendo por tanto los impuestos indirectos), pero para cada uno de los sectores analizados se presentan los CLU a partir del Valor Añadido Bruto del sector ofrecido por el Eustat, sin tener en cuenta los impuestos indirectos, puesto que estos no se ofrecen desglosados por sectores (no lo hace el Eustat ni la Hacienda Foral de Gipuzkoa). Ver nota metodológica anterior. 
En el sector agropecuario observamos una caída notable y persistente de la ocupación y el empleo, con un repunte en 2010 y bajadas posteriores. Se reduce la parte de personas asalariadas entre las ocupadas durante todo el periodo. La tasa de completitud (inversa de la parcialidad media de los empleos) es baja y estable.

El VAB del sector permanece estable en todo el periodo, con una caída entre 2008-2011 y recuperación en 2012. La productividad y remuneración horaria de este sector son bajas, con una tendencia al alza de la primera y un relativo estancamiento de la segunda. Los CLU Reales son altos pero decrecientes en el conjunto del periodo, muy notablemente en 2012.

Hay un aumento muy importante de la jornada anual media de las personas asalariadas, lo cuál no puede sino mostrar una intensificación de los trabajos realizados por menos personas.

Las bajas productividades en el sector primario, la alta tasa de parcialidad de los asalariados ligada a la estacionalidad de la actividad, así como también la alta y creciente presencia de personas no asalariadas en el mismo (propietarias de tierra en su mayoría) dificultan políticas de RTT, a pesar de las caídas de los CLU en los últimos 20 años, el aguante de la ocupación y el empleo en estos tiempos de crisis y el relativo dinamismo de las contrataciones observado en 2014.

Tabla 3

Indicadores sociolaborales. Metalurgia y productos metálicos

\begin{tabular}{|c|c|c|c|c|c|c|c|}
\hline Datos de síntesis & 1995 & 2007 & 2008 & 2009 & 2010 & 2011 & 2012 \\
\hline Personas ocupadas & 22.363 & 35.207 & 34.258 & 29.825 & 28.100 & 27.816 & 26.414 \\
\hline Personas asalariadas & 20.483 & 34.339 & 33.545 & 29.306 & 27.602 & 27.340 & 26.024 \\
\hline$\%$ asalariadas/empleadas del sector & $92 \%$ & $98 \%$ & $98 \%$ & $98 \%$ & $98 \%$ & $98 \%$ & $99 \%$ \\
\hline Puestos de trabajo asalariado & 20.648 & 34.615 & 33.815 & 29.542 & 27.825 & 27.562 & 26.236 \\
\hline T. completitud asalariadas $\left(^{*}\right)$ & $98,6 \%$ & $97,9 \%$ & $97,8 \%$ & $97,3 \%$ & $95,7 \%$ & $96,9 \%$ & $96,9 \%$ \\
\hline VAB sectorial (miles $€$ ) & 873.424 & 2.466 .445 & 2.287 .113 & 1.485 .205 & 1.548 .744 & 1.616 .139 & 1.558 .792 \\
\hline Productividad horaria población ocupada & $22,3 €$ & $42,1 €$ & $39,9 €$ & $31,1 €$ & $33,7 €$ & $35,3 €$ & $36,0 €$ \\
\hline Remuneración por hora asalariada & $15,0 €$ & $23,2 €$ & $24,9 €$ & $26,0 €$ & $26,0 €$ & $27,0 €$ & $27,4 €$ \\
\hline Costes laborales unitarios reales & $68 \%$ & $55 \%$ & $62 \%$ & $84 \%$ & $77 \%$ & $76 \%$ & $76 \%$ \\
\hline Horas anuales asalariados t. completo & 1.749 & 1.671 & 1.681 & 1.618 & 1.681 & 1.661 & 1.654 \\
\hline Horas anuales por asalariado reales & 1.738 & 1.649 & 1.656 & 1.588 & 1.621 & 1.622 & 1.616 \\
\hline \multicolumn{5}{|c|}{${ }^{*} \mathrm{~T}$. completitud $=$ Puestos E.T.C./Puestos total. } & \multicolumn{3}{|c|}{ Contratos iniciales $2014\left({ }^{*}\right)$} \\
\hline \multirow[t]{4}{*}{ Fuente: EUSTAT. } & & & & & \multirow{2}{*}{\multicolumn{2}{|c|}{$\begin{array}{l}\text { Hombres } \\
\text { Mujeres }\end{array}$}} & 19.115 \\
\hline & & & & & & & 7.350 \\
\hline & & & & & \multicolumn{3}{|c|}{ * Total Metal+Maquin+Mat.Transp } \\
\hline & & & & & \multicolumn{3}{|c|}{ Fuente: SEPE. } \\
\hline
\end{tabular}


La ocupación en el sector de la Metalurgia — cada vez más asalariada y menos auto empleada - muestra un importante aumento entre 1995 y 2007 y una notable caída entre 2008 y 2012. La completitud de las personas empleadas es cercana al $100 \%$ aunque se observa un ligero descenso en el último periodo de crisis.

El VAB del metal en Gipuzkoa evoluciona en el mismo sentido que el nivel de ocupación, con incrementos hasta el 2007 y caídas muy importantes desde entonces. La productividad horaria de la población ocupada era cercana a la media provincial, aunque en los primeros años de la crisis tuvo caídas notables que se han empezado a recuperar entre 2010 y 2012. La remuneración por hora asalariada está ligeramente por encima de la media. Los CLU se han reducido en el periodo pre-crisis (1995-2007) pero se disparan con la fuerte contracción del volumen de empleo en 2009. Desde entonces vuelve a mostrar un descenso, lejos de alcanzar los niveles de 2007.

Las jornadas anuales se han reducido en unas 100 horas desde 1995 hasta 2012. En los últimos años se dan ligeros descensos también.

La caída del VAB, el aumento de los CLU, las jornadas de las personas asalariadas a tiempo completo por debajo de la media provincial no invitan a hacer políticas de RTT que, en cualquier caso, si que hubieran podido ser una alternativa a la fuerte destrucción de empleo de los últimos años. 
Tabla 4

Indicadores sociolaborales. Maquinaria y equipo

\begin{tabular}{|c|c|c|c|c|c|c|c|}
\hline Datos de síntesis & 1995 & 2007 & 2008 & 2009 & 2010 & 2011 & 2012 \\
\hline Personas ocupadas & 10.856 & 15.272 & 15.114 & 14.133 & 13.949 & 13.863 & 13.767 \\
\hline Personas asalariadas & 10.738 & 15.106 & 14.950 & 13.980 & 13.788 & 13.703 & 13.609 \\
\hline$\%$ asalariadas/empleadas del sector & $98,9 \%$ & $98,9 \%$ & $98,9 \%$ & $98,9 \%$ & $98,8 \%$ & $98,8 \%$ & $98,9 \%$ \\
\hline Puestos de trabajo asalariado & 10.818 & 15.218 & 15.061 & 14.083 & 13.890 & 13.804 & 13.710 \\
\hline T. completitud asalariadas $\left({ }^{*}\right)$ & $97,5 \%$ & $97,3 \%$ & $98,3 \%$ & $97,3 \%$ & $97,0 \%$ & $98,1 \%$ & $98,1 \%$ \\
\hline VAB sectorial (miles $€$ ) & 436.784 & 955.543 & 992.679 & 941.716 & 997.093 & 1.074 .782 & 1.085 .642 \\
\hline Productividad horaria población ocupada & $22,4 €$ & $37,3 €$ & $38,9 €$ & $40,1 €$ & $43,1 €$ & $46,3 €$ & $47,6 €$ \\
\hline Remuneración por hora asalariada & $15,8 €$ & $24,5 €$ & $26,2 €$ & $26,8 €$ & $26,8 €$ & $28,0 €$ & $28,6 €$ \\
\hline Costes laborales unitarios reales & $71 \%$ & $66 \%$ & $67 \%$ & $67 \%$ & $62 \%$ & $61 \%$ & $60 \%$ \\
\hline Horas anuales asalariados t. completo & 1.815 & 1.699 & 1.690 & 1.681 & 1.682 & 1.674 & 1.656 \\
\hline Horas anuales por asalariado reales & 1.782 & 1.666 & 1.674 & 1.649 & 1.643 & 1.654 & 1.636 \\
\hline \multicolumn{5}{|c|}{ * T. completitud $=$ Puestos E.T.C./Puestos total. } & \multicolumn{3}{|c|}{ Contratos iniciales $2014\left(^{*}\right)$} \\
\hline \multirow{2}{*}{\multicolumn{5}{|c|}{ Fuente: EUSTAT. }} & \multicolumn{2}{|l|}{ Hombres } & 19.115 \\
\hline & & & & & \multicolumn{2}{|l|}{ Mujeres } & 7.350 \\
\hline & & & & & ${ }^{*}$ Total M & al+Maqui & Mat.Transp \\
\hline & & & & & Fuente: S & & \\
\hline
\end{tabular}

El empleo asalariado en el sector de las industrias de Maquinaría y Equipo aumenta notoriamente entre 1995 y 2007. Se da una caída del empleo asalariado en el periodo de crisis hasta el 2012, siendo esta la condición de la casi totalidad de los ocupados del sector (pocos autónomos o auto-empleados). La alta tasa de completitud del empleo asalariado muestra una escasa parcialidad de los puestos.

El VAB del sector sigue aumentando ligeramente en los últimos años, al tiempo que se dan notables incrementos de productividad. La evolución más moderada de las remuneraciones por hora asalariada nos muestran un descenso notable de los CLU, que se sitúan en la media de la economía gipuzkoana.

La jornada anual media de los asalariados se ha reducido en el periodo 1995-2007 y desde el 2009 no tiene descensos importantes.

En el caso de la de Maquinaría y Equipo, las políticas de RTT son viables dado el relativo dinamismo global de las contrataciones en las industrias manu- 
factureras ${ }^{3}$, así como los aumentos de excedentes y productividades en este sector específico, lo que muestra una caída de sus CLU que permitirían un mejor reparto del empleo vía la RTT sin reducciones de salarios.

Tabla 5

Indicadores sociolaborales. Material de transporte

\begin{tabular}{lccccccc}
\hline \multicolumn{1}{c}{ Datos de síntesis } & 1995 & 2007 & 2008 & 2009 & 2010 & 2011 & 2012 \\
\hline Personas ocupadas & 4.513 & 5.725 & 5.858 & 5.668 & 5.789 & 5.457 & 5.361 \\
Personas asalariadas & 4.456 & 5.723 & 5.857 & 5.667 & 5.785 & 5.454 & 5.361 \\
\% asalariadas/empleadas del sector & $99 \%$ & $100 \%$ & $100 \%$ & $100 \%$ & $100 \%$ & $100 \%$ & $100 \%$ \\
Puestos de trabajo asalariado & 4.486 & 5.763 & 5.897 & 5.706 & 5.825 & 5.491 & 5.398 \\
T. completitud asalariadas $\left(^{*}\right)$ & $92,6 \%$ & $93,1 \%$ & $91,8 \%$ & $90,4 \%$ & $90,6 \%$ & $92,8 \%$ & $92,7 \%$ \\
\hline \multicolumn{1}{c}{ VAB sectorial (miles $€)$} & 198.955 & 509.899 & 564.954 & 491.879 & 552.868 & 602.898 & 580.185 \\
\hline Productividad horaria población ocupada & $25,6 €$ & $55,1 €$ & $60,5 €$ & $55,5 €$ & $61,0 €$ & $68,9 €$ & $77,1 €$ \\
Remuneración por hora asalariada & $18,0 €$ & $28,5 €$ & $29,7 €$ & $33,0 €$ & $32,7 €$ & $33,5 €$ & $39,0 €$ \\
Costes laborales unitarios reales & $71 \%$ & $52 \%$ & $49 \%$ & $59 \%$ & $54 \%$ & $49 \%$ & $51 \%$ \\
\hline Horas anuales asalariados t. completo & 1.837 & 1.713 & 1.712 & 1.704 & 1.704 & 1.704 & 1.491 \\
Horas anuales por asalariado reales & 1.713 & 1.605 & 1.583 & 1.552 & 1.555 & 1.591 & 1.392 \\
\hline
\end{tabular}

* T. completitud $=$ Puestos E.T.C./Puestos total.

Fuente: EUSTAT.

\begin{tabular}{lr}
\multicolumn{2}{c}{ Contratos iniciales $2014\left(^{*}\right)$} \\
\hline Hombres & 19.115 \\
Mujeres & 7.350 \\
\hline$*$
\end{tabular}

* Total Metal+Maquin+Mat.Transp

Fuente: SEPE

El volumen de empleo asalariado en la industria del Material de transporte es estable en el conjunto del periodo, con aumentos desde 1995 y ligeros retrocesos en los 5 primeros años de ajuste. La tasa de salarización de la ocupación en el sector es del 100\%.

El VAB sigue aumentando en el periodo de crisis y tantos las productividades como las remuneraciones horarias tienes evoluciones muy positivas en estos años recientes. A pesar de los fuertes descensos de los CLU desde 1995 este indicador permanece estable desde 2007.

3 Para el conjunto de las industrias manufactureras (metalurgia, maquinaría/equipo y material de transporte, el volumen de contratación es de 26.456 contratos en 2014, en relación a un volumen total de empleo de estas tres ramas en 2012 de 45.344 puestos asalariados. 
La jornada anual media las personas asalariadas en este sector se reduce notablemente en el periodo 2007-2012, en especial en este último ańo dónde pasa de 1.591 a 1.392 .

A pesar de la dinámica de contratación (menor que en el resto de industrias manufactureras), la industria de material de transporte ya efectúa una política equilibrada en Gipuzkoa en lo relativo a jornada laboral y remuneración de las personas asalariadas, pero siendo los CLU bajos y descendientes las políticas de RTT pueden tener viabilidad.

Tabla 6

Indicadores sociolaborales.

Construcción

\begin{tabular}{|c|c|c|c|c|c|c|c|}
\hline Datos de síntesis & 1995 & 2007 & 2008 & 2009 & 2010 & 2011 & 2012 \\
\hline Personas ocupadas & 17.440 & 31.518 & 30.672 & 28.540 & 26.593 & 24.098 & 22.109 \\
\hline Personas asalariadas & 11.623 & 22.849 & 22.235 & 20.689 & 18.860 & 17.090 & 15.186 \\
\hline$\%$ asalariadas/empleadas del sector & $67 \%$ & $72 \%$ & $72 \%$ & $72 \%$ & $71 \%$ & $71 \%$ & $69 \%$ \\
\hline Puestos de trabajo asalariado & 11.773 & 23.145 & 22.523 & 20.957 & 19.380 & 15.562 & 16.114 \\
\hline T. completitud asalariadas $\left(^{*}\right)$ & $96,3 \%$ & $96,3 \%$ & $96,3 \%$ & $96,3 \%$ & $96,6 \%$ & $97,3 \%$ & $93,6 \%$ \\
\hline VAB sectorial (miles $€$ ) & 652.744 & 2.025 .448 & 2.000 .343 & 1.806 .282 & 1.718 .310 & 1.561 .690 & 1.380 .534 \\
\hline Productividad horaria población ocupada & $21,0 €$ & $36,9 €$ & $37,8 €$ & $36,6 €$ & $36,8 €$ & $36,9 €$ & $36,2 €$ \\
\hline Remuneración por hora asalariada & $19,9 €$ & $31,2 €$ & $33,7 €$ & $35,2 €$ & $33,8 €$ & $34,5 €$ & $33,0 €$ \\
\hline Costes laborales unitarios reales & $94 \%$ & $85 \%$ & $89 \%$ & $96 \%$ & $92 \%$ & $94 \%$ & $91 \%$ \\
\hline Horas anuales asalariados t. completo & 1.801 & 1.759 & 1.745 & 1.753 & 1.756 & 1.740 & 1.802 \\
\hline Horas anuales por asalariado reales & 1.757 & 1.717 & 1.703 & 1.711 & 1.738 & 1.730 & 1.790 \\
\hline \multicolumn{6}{|c|}{ * T. completitud = Puestos E.T.C./Puestos total. } & \multicolumn{2}{|c|}{ Contratos iniciales 2014} \\
\hline \multirow{2}{*}{\multicolumn{6}{|c|}{ Fuente: EUSTAT. }} & Hombres & 7.698 \\
\hline & & & & & & Mujeres & 394 \\
\hline
\end{tabular}

Fuente: SEPE.

Al tiempo que el volumen de personas asalariadas en la Construcción gipuzkoana se dobla entre 1995 y 2007, la parte de asalariadas sobre el total de empleadas aumenta por encima de los dos tercios, lo que en cualquier caso muestra el carácter de autónomo o micro-empresarial de una parte sustancial de la mano de obra.

Desde el 2007 hasta el 2012 se destruye en torno a un tercio del empleo del sector, cayendo también la tasa de salarización. En esta destrucción de empleo 
baja también la tasa de completitud (inversa de la de parcialidad) de las personas empleadas en el sector.

Si el VAB Se había triplicado en términos nominales entre 1995 y 2007 , desde el 2009 cae notablemente año tras año. La productividad horaria está ligeramente por debajo de la media provincial y se ha estancado en el periodo 20082012. La remuneración por hora asalariada está bastante por encima de la media provincial, aunque se reduce en términos nominales (y, por tanto, más en términos reales) de 2007 a 2012.

Los CLU reales se han reducido desde 1995, pero son altos en relación a la media provincial. En el 2008 y 2009 aumentan fruto de la destrucción del empleo peor remunerado. En 2010 y 2012 han bajado de nuevo fruto seguramente de ajustes de plantillas más estructurales y, seguramente, mejor remunerados.

Las jornadas anuales medias son muy altas en la construcción, entre 100 y 200 horas más que la media provincial. Se habían reducido algo entre 1995 y 2007 pero vuelve a aumentar en el actual periodo de crisis del sector, dónde la destrucción de empleo genera paradójicamente una intensificación del trabajo, seguramente por destrucciones de empleo por encima de las necesidades de ajuste fruto de la contracción de la actividad y volumen de negocio sectorial.

Esta intensificación del trabajo, el descenso de la parte de asalariados y la propia evolución del empleo y el aumento del tiempo parcial en la construcción gipuzkoana podrían apuntar las ventajas de realizar políticas de RTT, que aún así no parecen de fácil inserción, vistos los malos datos del sector, sus altos CLU y el estancamiento de la productividad. 
Tabla 7

Indicadores sociolaborales.

Comercio y reparación de vehículos

\begin{tabular}{|c|c|c|c|c|c|c|c|}
\hline Datos de síntesis & 1995 & 2007 & 2008 & 2009 & 2010 & 2011 & 2012 \\
\hline Personas ocupadas & 35.810 & 46.317 & 46.707 & 45.218 & 44.521 & 44.466 & 43.096 \\
\hline Personas asalariadas & 23.814 & 37.409 & 37.480 & 36.291 & 35.715 & 35.652 & 34.706 \\
\hline$\%$ asalariadas/empleadas del sector & $67 \%$ & $81 \%$ & $80 \%$ & $80 \%$ & $80 \%$ & $80 \%$ & $81 \%$ \\
\hline Puestos de trabajo asalariado & 24.188 & 37.996 & 38.069 & 36.861 & 36.275 & 36.211 & 35.250 \\
\hline T. completitud asalariadas $\left({ }^{*}\right)$ & $95,4 \%$ & $95,7 \%$ & $95,6 \%$ & $94,9 \%$ & $94,5 \%$ & $95,2 \%$ & $95,2 \%$ \\
\hline VAB sectorial (miles $€$ ) & 965.455 & 1.979 .180 & 2.070 .797 & 2.040 .880 & 2.076 .666 & 2.106 .410 & 2.086 .553 \\
\hline Productividad horaria población ocupada & $15,4 €$ & $24,2 €$ & $25,2 €$ & $26,0 €$ & $27,0 €$ & $27,3 €$ & $28,0 €$ \\
\hline Remuneración por hora asalariada & $10,9 €$ & $16,1 €$ & $16,5 €$ & $17,0 €$ & $18,5 €$ & $18,8 €$ & $19,0 €$ \\
\hline Costes laborales unitarios reales & $71 \%$ & $66 \%$ & $66 \%$ & $65 \%$ & $69 \%$ & $69 \%$ & $68 \%$ \\
\hline Horas anuales asalariados t. completo & 1.783 & 1.699 & 1.692 & 1.722 & 1.724 & 1.711 & 1.704 \\
\hline Horas anuales por asalariado reales & 1.728 & 1.651 & 1.642 & 1.660 & 1.655 & 1.655 & 1.648 \\
\hline \multicolumn{6}{|c|}{ * T. completitud = Puestos E.T.C./Puestos total. } & \multicolumn{2}{|c|}{ Contratos iniciales 2014} \\
\hline \multirow{2}{*}{\multicolumn{6}{|c|}{ Fuente: EUSTAT. }} & Hombres & 9.926 \\
\hline & & & & & & Mujeres & 16.729 \\
\hline
\end{tabular}

Fuente: SEPE.

El sector del Comercio es el primer sector del empleo en Gipuzkoa. Aporta 43.000 efectivos al volumen total de ocupación laboral, muchos más que los siguientes en importancia como son la Metalurgia (26.600), la Educación (23.100), la Construcción (22.400) y la Hostelería (18.900).

En los fuertes incrementos de ocupación entre 1995 y 2007 cabe destacar los aumentos de la tasa de salarización desde $2 / 3$ a más de $80 \%$. El volumen de empleo y ocupación cae en estos años de crisis, siendo los momentos de mayor ajuste de plantillas el 2009 y el 2012.

Tras aumentar notablemente desde 1995, el VAB nominal se ha mantenido estable entre 2008 y 2012. La productividad ha seguido aumentando en este último periodo y la remuneración de los asalariados se estanca en términos reales, estando ambos indicadores muy por debajo de las medias provinciales. Los CLU también se mantienen estables, situándose en todo momento por debajo de los que se observan en 1995.

Las jornadas anuales medias son más elevadas que la medía, la tasa de completitud en torno al 95\% y en evolución vemos que el ajuste del volumen de 
empleo desde 2008 no se ha saldado con alteraciones estructurales en la jornada media.

El volumen importante de contratación en 2014 -más concentrado en las mujeres - , junto al resto de datos enumerados en esta sección, nos permite apuntar que el comercio también es un sector dónde la RTT podrían tener efectos positivos, a pesar de que su evolución en los últimos años y en general sus bajas productividades y CLU por encima de la media no los convierte en la zona preferencial de estas medidas.

Tabla 8

Indicadores sociolaborales. Transporte y almacenamiento

\begin{tabular}{|c|c|c|c|c|c|c|c|}
\hline Datos de síntesis & 1995 & 2007 & 2008 & 2009 & 2010 & 2011 & 2012 \\
\hline Personas ocupadas & 11.009 & 14.350 & 14.813 & 13.864 & 13.673 & 13.581 & 13.083 \\
\hline Personas asalariadas & 8.225 & 10.178 & 10.517 & 10.000 & 9.802 & 9.769 & 9.436 \\
\hline$\%$ asalariadas/empleadas del sector & $75 \%$ & $71 \%$ & $71 \%$ & $72 \%$ & $72 \%$ & $72 \%$ & $72 \%$ \\
\hline Puestos de trabajo asalariado & 8.392 & 10.384 & 10.731 & 10.203 & 10.002 & 9.967 & 9.627 \\
\hline T. completitud asalariadas $\left(^{*}\right)$ & $98,5 \%$ & $98,5 \%$ & $98,6 \%$ & $97,4 \%$ & $96,5 \%$ & $96,5 \%$ & $96,6 \%$ \\
\hline VAB sectorial (miles $€$ ) & 364.922 & 810.793 & 847.504 & 867.717 & 834.009 & 875.231 & 871.058 \\
\hline Productividad horaria población ocupada & $18,7 €$ & $31,8 €$ & $32,2 €$ & $35,4 €$ & $34,5 €$ & $37,7 €$ & $39,0 €$ \\
\hline Remuneración por hora asalariada & $13,7 €$ & $24,4 €$ & $25,1 €$ & $26,4 €$ & $31,4 €$ & $31,0 €$ & $30,5 €$ \\
\hline Costes laborales unitarios reales & $73 \%$ & $77 \%$ & $78 \%$ & $75 \%$ & $91 \%$ & $82 \%$ & $78 \%$ \\
\hline Horas anuales asalariados t. completo & 1.709 & 1.668 & 1.668 & 1.661 & 1.659 & 1.674 & 1.684 \\
\hline Horas anuales por asalariado reales & 1.717 & 1.677 & 1.677 & 1.650 & 1.634 & 1.648 & 1.660 \\
\hline \multicolumn{5}{|c|}{${ }^{*}$ T. completitud = Puestos E.T.C./Puestos total. } & \multicolumn{3}{|c|}{ Contratos iniciales 2014} \\
\hline \multirow{2}{*}{\multicolumn{5}{|c|}{ Fuente: EUSTAT. }} & Hombres & & 8.879 \\
\hline & & & & & Mujeres & & 2.811 \\
\hline
\end{tabular}

Fuente: SEPE.

La evolución de la ocupación y el empleo en el sector del Transporte y Almacenamiento nos muestra una situación de aumento desde 1995 y de ajuste de plantillas en 2009, con descensos no tan marcados en los ańos siguientes. La parte de asalariadas del sector se ha reducido en este periodo, a excepción del 2009 dónde aumenta un punto - lo que significa que el ajuste de plantillas ha sido más acusado entre autónomos y subcontratados-.

El VAB del sector es más del doble en 2007 que en 1995, manteniéndose estable en términos nominales de 2007 a 2012. La productividad horaria está 
un poco por debajo de la media provincial y ha aumentado notablemente en los últimos años, especialmente en 2009 fruto del ajuste de plantillas por el lado de las pero remuneradas. La remuneración horaria ha aumentado por encima de la media, lo cual muestra unos CLU con una ligera tendencia al alza entre 1995 y 2010. Por contra los CLU reales muestra descensos notables en 2011 y 2012.

Las jornadas medias anuales son altas y aumentan en 2011 y 2012, a pesar del descenso moderado a lo largo de todo el periodo. Así mismo el nivel de contratación en 2014 nos muestra un sector dinámico. Todo lo expuesto deja a entrever que sí se dan las condiciones para una política de RTT porque la caída del empleo y la existencia de un tercio de autónomos en el sector no impide un creciente VAB sectorial, aumentos de productividad y una caída importante de los CLU

Tabla 9

Indicadores sociolaborales. Hostelería

\begin{tabular}{|c|c|c|c|c|c|c|c|}
\hline Datos de síntesis & 1995 & 2007 & 2008 & 2009 & 2010 & 2011 & 2012 \\
\hline Personas ocupadas & 12.050 & 16.680 & 17.114 & 17.251 & 17.199 & 17.548 & 18.251 \\
\hline Personas asalariadas & 7.744 & 13.495 & 13.847 & 13.958 & 13.917 & 14.198 & 14.399 \\
\hline$\%$ asalariadas/empleadas del sector & $64 \%$ & $81 \%$ & $81 \%$ & $81 \%$ & $81 \%$ & $81 \%$ & $79 \%$ \\
\hline Puestos de trabajo asalariado & 8.037 & 14.006 & 14.371 & 14.486 & 14.443 & 14.735 & 14.943 \\
\hline T. completitud asalariadas $\left(^{*}\right)$ & $95,0 \%$ & $94,4 \%$ & $94,3 \%$ & $94,0 \%$ & $92,6 \%$ & $93,0 \%$ & $93,0 \%$ \\
\hline VAB sectorial (miles $€$ ) & 338.211 & 760.026 & 794.333 & 806.053 & 871.476 & 910.811 & 945.712 \\
\hline Productividad horaria población ocupada & $14,5 €$ & $25,5 €$ & $26,0 €$ & $26,3 €$ & $28,5 €$ & $30,2 €$ & $30,1 €$ \\
\hline Remuneración por hora asalariada & $9,4 €$ & $16,6 €$ & $17,4 €$ & $18,3 €$ & $20,7 €$ & $21,7 €$ & $22,7 €$ \\
\hline Costes laborales unitarios reales & $65 \%$ & $65 \%$ & $67 \%$ & $69 \%$ & $72 \%$ & $75 \%$ & $75 \%$ \\
\hline Horas anuales asalariados t. completo & 1.836 & 1.670 & 1.670 & 1.675 & 1.700 & 1.691 & 1.684 \\
\hline Horas anuales por asalariado reales & 1.811 & 1.636 & 1.634 & 1.633 & 1.633 & 1.633 & 1.626 \\
\hline \multicolumn{5}{|l|}{ * T. completitud = Puestos E.T.C./Puestos total. } & \multicolumn{3}{|c|}{ Contratos iniciales 2014} \\
\hline \multirow{2}{*}{\multicolumn{5}{|c|}{ Fuente: EUSTAT. }} & \multicolumn{2}{|l|}{ Hombres } & 13.199 \\
\hline & & & & & \multicolumn{2}{|l|}{ Mujeres } & 23.875 \\
\hline
\end{tabular}

Fuente: SEPE.

El volumen de ocupación y empleo aumentan en la Hostelería a lo largo de todo el periodo, aumentando notablemente la parte asalariada de las personas ocupadas en el sector. 
El VAB también aumenta a lo largo de todo el periodo, con una productividad y remuneración horaria por debajo de la media provincial. Los CLU aumentan en los últimos años.

Las jornadas anuales medias de las personas asalariadas están algo por encima de las del conjunto de Gipuzkoa, pero han bajado mucho entre 1995 y 2007, permaneciendo estables en los años siguientes.

El volumen de contratos iniciales en 2014 es muy alto, más concentrado en las mujeres.

Todos los indicadores apuntarían a la posibilidad de políticas de RTT, si no fuera por los aumentos de los CLU que hacen difíciles estas medidas.

Tabla 10

Indicadores sociolaborales. Actividades financieras y seguros

\begin{tabular}{|c|c|c|c|c|c|c|c|}
\hline Datos de síntesis & 1995 & 2007 & 2008 & 2009 & 2010 & 2011 & 2012 \\
\hline Personas ocupadas & 6.518 & 6.993 & 7.107 & 7.088 & 6.654 & 6.503 & 6.242 \\
\hline Personas asalariadas & 5.983 & 6.302 & 6.672 & 6.656 & 6.224 & 6.079 & 5.825 \\
\hline$\%$ asalariadas/empleadas del sector & $92 \%$ & $90 \%$ & $94 \%$ & $94 \%$ & $94 \%$ & $93 \%$ & $93 \%$ \\
\hline Puestos de trabajo asalariado & 6.042 & 6.363 & 6.465 & 6.721 & 6.285 & 6.139 & 5.883 \\
\hline T. completitud asalariadas $(*)$ & $96,7 \%$ & $97,1 \%$ & $96,8 \%$ & $96,8 \%$ & $97,5 \%$ & $97,5 \%$ & $97,6 \%$ \\
\hline VAB sectorial (miles $€$ ) & 640.523 & 1.285 .058 & 1.319 .045 & 1.307 .484 & 1.220 .483 & 1.198 .872 & 1.211.274 \\
\hline Productividad horaria población ocupada & $57,9 €$ & $109,5 €$ & $110,4 €$ & $110,9 €$ & $109,5 €$ & $110,0 €$ & $115,8 €$ \\
\hline Remuneración por hora asalariada & $17,3 €$ & $26,6 €$ & $26,8 €$ & $28,5 €$ & $30,4 €$ & $31,6 €$ & $32,8 €$ \\
\hline Costes laborales unitarios reales & $30 \%$ & $24 \%$ & $24 \%$ & $26 \%$ & $28 \%$ & $29 \%$ & $28 \%$ \\
\hline Horas anuales asalariados t. completo & 1.710 & 1.685 & 1.765 & 1.682 & 1.685 & 1.684 & 1.710 \\
\hline Horas anuales por asalariado reales & 1.670 & 1.653 & 1.655 & 1.644 & 1.659 & 1.659 & 1.685 \\
\hline \multicolumn{5}{|c|}{${ }^{*}$ T. completitud $=$ Puestos E.T.C./Puestos total. } & \multicolumn{3}{|c|}{ Contratos iniciales 2014} \\
\hline \multirow{2}{*}{\multicolumn{5}{|c|}{ Fuente: EUSTAT. }} & Hombres & & 323 \\
\hline & & & & & Mujeres & & 746 \\
\hline
\end{tabular}

Fuente: SEPE.

El volumen de empleo en las Finanzas se mantiene estable en todo el perido con ligeros ajustes en los últimos ańos. La parte de asalariadas entre las ocupadas del sector aumenta en el último periodo y la tasa de completitud se mantiene alta. 
El VAB sectorial se dobla en términos nominales entre 1995 y 2008, con un ligero retroceso en los ańos siguientes. La productividad horaria es la más alta de los sectores estudiados y la remuneración está muy por encima de la media provincial. Por tanto, los CLU son bajos y decrecientes en el periodo, con una ligera inversión de esta tendencia en los últimos años.

La jornada media anual está bastante por encima de la media.

Por todo lo expuesto, consideramos que sí se dan las condiciones para una política de RTT porque estamos hablando del sector con mayor productividad por hora asalariada, una tasa de completitud muy alta, un VAB estable en los primeros cinco años de crisis y, sobre todo, unos CLU muy bajos y estables al tiempo que la jornada anual media de una persona asalariada no ha variado o incluso tiene un ligero incremento desde 1995 hasta el 2007.

Tabla 11

Indicadores sociolaborales.

Consultoría y actividades técnicas

\begin{tabular}{|c|c|c|c|c|c|c|c|}
\hline \multicolumn{8}{|c|}{ Administración Pública y Defensa } \\
\hline Datos de síntesis & 1995 & 2007 & 2008 & 2009 & 2010 & 2011 & 2012 \\
\hline Personas ocupadas & 15.429 & 17.659 & 18.065 & 18.245 & 18.543 & 18.307 & 18.123 \\
\hline Personas asalariadas & 15.429 & 17.659 & 18.065 & 18.245 & 18.545 & 18.308 & 18.125 \\
\hline$\%$ asalariadas/empleadas del sector & $100 \%$ & $100 \%$ & $100 \%$ & $100 \%$ & $100 \%$ & $100 \%$ & $100 \%$ \\
\hline Puestos de trabajo asalariado & 15.609 & 17.865 & 18.276 & 18.458 & 18.760 & 18.521 & 18.336 \\
\hline T. completitud asalariadas $(*)$ & $98,0 \%$ & $98,0 \%$ & $97,9 \%$ & $97,9 \%$ & $97,9 \%$ & $97,9 \%$ & $97,9 \%$ \\
\hline VAB sectorial (miles $€$ ) & 427.299 & 818.669 & 898.532 & 899.554 & 897.406 & 917.379 & 905.216 \\
\hline Productividad horaria población ocupada & $16,8 €$ & $28,7 €$ & $30,9 €$ & $30,6 €$ & $30,8 €$ & $31,9 €$ & $31,5 €$ \\
\hline Remuneración por hora asalariada & $15,0 €$ & $24,7 €$ & $26,9 €$ & $26,9 €$ & $27,2 €$ & $27,7 €$ & $27,0 €$ \\
\hline Costes laborales unitarios reales & $90 \%$ & $86 \%$ & $87 \%$ & $88 \%$ & $88 \%$ & $87 \%$ & $86 \%$ \\
\hline Horas anuales asalariados t. completo & 1.667 & 1.627 & 1.627 & 1.627 & 1.600 & 1.600 & 1.626 \\
\hline Horas anuales por asalariado reales & 1.652 & 1.613 & 1.611 & 1.611 & 1.585 & 1.584 & 1.611 \\
\hline \multicolumn{5}{|c|}{${ }^{*}$ T. completitud = Puestos E.T.C./Puestos total. } & \multicolumn{3}{|c|}{ Contratos iniciales $2014\left(^{*}\right)$} \\
\hline \multirow{2}{*}{\multicolumn{5}{|c|}{ Fuente: EUSTAT }} & \multirow{2}{*}{\multicolumn{2}{|c|}{$\begin{array}{l}\text { Hombres } \\
\text { Mujeres }\end{array}$}} & 14.600 \\
\hline & & & & & & & 19.550 \\
\hline & & & & & \multicolumn{3}{|c|}{ * Serv. Aux.+Admin.Púb./Def. } \\
\hline
\end{tabular}

El sector de la Consultoría y actividades técnicas ha multiplicado por más de dos su volumen de empleo en el periodo, permaneciendo estable desde el 
2007 hasta el 2012. Si en 1995 las personas ocupadas en el sector eran casi en su totalidad asalariadas, esta relación desciende para 2007, situándose en 2012 un poco por encima de las $3 / 4$ partes las asalariadas sobre el total. Este descenso muy importante de la tasa de salarización permite constatar el creciente carácter de auto-empleo o de prestaciones micro-empresariales de una parte creciente de estas actividades.

EL VAB del sector aumenta a lo largo de todo el periodo, siendo la productividad y la remuneración horaria nominal crecientes. Esta relación nos muestra unos CLU que aumentan notablemente a lo largo del periodo.

La jornada anual media se reduce entre 1995 y 2007, momento a partir del cuál permanece estable.

El volumen de contrataciones iniciales en 2014 es alto en relación al empleo del sector.

Además de la propia naturaleza de las actividades del sector, la evolución de los CLU, las jornadas anuales y la no reducción de las plantillas nos hace pensar que este sector no será preferencial en lo que a políticas de RTT se refiere.

Tabla 12

Indicadores sociolaborales.

Servicios auxiliares

\begin{tabular}{|c|c|c|c|c|c|c|c|}
\hline Datos de síntesis & 1995 & 2007 & 2008 & 2009 & 2010 & 2011 & 2012 \\
\hline Personas ocupadas & 6.201 & 14.169 & 14.331 & 14.211 & 14.182 & 14.043 & 13.591 \\
\hline Personas asalariadas & 5.294 & 12.883 & 13.091 & 12.939 & 12.916 & 12.790 & 12.334 \\
\hline$\%$ asalariadas/empleadas del sector & $85 \%$ & $91 \%$ & $91 \%$ & $91 \%$ & $91 \%$ & $91 \%$ & $91 \%$ \\
\hline Puestos de trabajo asalariado & 5.615 & 13.663 & 13.884 & 13.723 & 13.696 & 13.569 & 13.090 \\
\hline T. completitud asalariadas $\left({ }^{*}\right)$ & $89,7 \%$ & $88,0 \%$ & $87,6 \%$ & $88,0 \%$ & $87,3 \%$ & $87,3 \%$ & $87,2 \%$ \\
\hline VAB sectorial (miles $€$ ) & 137.671 & 365.012 & 395.290 & 393.063 & 404.292 & 419.264 & 415.665 \\
\hline Productividad horaria población ocupada & $12,1 €$ & $14,5 €$ & $15,6 €$ & $15,9 €$ & $16,4 €$ & $18,2 €$ & $18,7 €$ \\
\hline Remuneración por hora asalariada & $8,6 €$ & $12,7 €$ & $13,5 €$ & $13,8 €$ & $15,3 €$ & $15,3 €$ & $14,9 €$ \\
\hline Costes laborales unitarios reales & $71 \%$ & $87 \%$ & $87 \%$ & $87 \%$ & $93 \%$ & $84 \%$ & $80 \%$ \\
\hline Horas anuales asalariados t. completo & 1.803 & 1.734 & 1.737 & 1.716 & 1.701 & 1.702 & 1.685 \\
\hline Horas anuales por asalariado reales & 1.714 & 1.620 & 1.614 & 1.601 & 1.574 & 1.576 & 1.560 \\
\hline \multicolumn{5}{|c|}{${ }^{*}$ T. completitud $=$ Puestos E.T.C. $/$ Puestos total. } & \multicolumn{3}{|c|}{ Contratos iniciales $2014\left(^{*}\right)$} \\
\hline \multirow[t]{3}{*}{ Fuente: EUSTAT. } & & & & & \multirow{2}{*}{\multicolumn{2}{|c|}{$\begin{array}{l}\text { Hombres } \\
\text { Mujeres }\end{array}$}} & 14.600 \\
\hline & & & & & & & 19.550 \\
\hline & & & & & \multicolumn{3}{|c|}{$\begin{array}{l}\text { * Serv. Aux.+Admin.Púb./Def. } \\
\text { Fuente: SEPE. }\end{array}$} \\
\hline
\end{tabular}


Los servicios auxiliares aumentan notablemente el volumen de empleo en nuestro periodo, a pesar de darse un ligero descenso en los últimos años. Esta evolución hace aumentar la parte de asalariadas sobre el total de personas ocupadas. El empleo tiene un cierto grado de parcialidad, fruto de tasas de completitud bajas y decrecientes.

Por contra, la evolución positiva del VAB no se invierte en los últimos años, siendo así mismo las productividades y remuneraciones horarias bastante bajas en relación al conjunto de la economía de Gipuzkoa, pero crecientes en términos nominales. Los CLU aumentan entre 1995 y 2010, tendencia que se invierte en los ańos siguientes, siendo notables los descensos en 2011 y 2012.

Las jornadas anuales son más altas que la media provincial, con ligeros descensos del número anual de horas que continúan hasta 2012.

En este sector procede un aumento de los salarios, ya que se puede observar una evolución en el largo plazo de los CLU que no favorece una RTT A pesar de esto, es posible que su tendencia a la baja en los últimos ańos, el alto volumen de contrataciones en 2014 y el no estancamiento del volumen de negocio en el sector permitan una política de RTT.

Tabla 13

Indicadores sociolaborales. Administración pública y defensa

\begin{tabular}{|c|c|c|c|c|c|c|c|}
\hline Datos de síntesis & 1995 & 2007 & 2008 & 2009 & 2010 & 2011 & 2012 \\
\hline Personas ocupadas & 15.429 & 17.659 & 18.065 & 18.245 & 18.543 & 18.307 & 18.123 \\
\hline Personas asalariadas & 15.429 & 17.659 & 18.065 & 18.245 & 18.545 & 18.308 & 18.125 \\
\hline$\%$ asalariadas/empleadas del sector & $100 \%$ & $100 \%$ & $100 \%$ & $100 \%$ & $100 \%$ & $100 \%$ & $100 \%$ \\
\hline Puestos de trabajo asalariado & 15.609 & 17.865 & 18.276 & 18.458 & 18.760 & 18.521 & 18.336 \\
\hline T. completitud asalariadas $(*)$ & $98,0 \%$ & $98,0 \%$ & $97,9 \%$ & $97,9 \%$ & $97,9 \%$ & $97,9 \%$ & $97,9 \%$ \\
\hline VAB sectorial (miles $€$ ) & 427.299 & 818.669 & 898.532 & 899.554 & 897.406 & 917.379 & 905.216 \\
\hline Productividad horaria población ocupada & $16,8 €$ & $28,7 €$ & $30,9 €$ & $30,6 €$ & $30,8 €$ & $31,9 €$ & $31,5 €$ \\
\hline Remuneración por hora asalariada & $15,0 €$ & $24,7 €$ & $26,9 €$ & $26,9 €$ & $27,2 €$ & $27,7 €$ & $27,0 €$ \\
\hline Costes laborales unitarios reales & $90 \%$ & $86 \%$ & $87 \%$ & $88 \%$ & $88 \%$ & $87 \%$ & $86 \%$ \\
\hline Horas anuales asalariados t. completo & 1.667 & 1.627 & 1.627 & 1.627 & 1.600 & 1.600 & 1.626 \\
\hline Horas anuales por asalariado reales & 1.652 & 1.613 & 1.611 & 1.611 & 1.585 & 1.584 & 1.611 \\
\hline \multicolumn{5}{|c|}{${ }^{*}$ T. completitud $=$ Puestos E.T.C. $/$ Puestos total. } & \multicolumn{3}{|c|}{ Contratos iniciales $2014\left(^{*}\right)$} \\
\hline \multirow[t]{4}{*}{ Fuente: EUSTAT. } & & & & & \multirow{2}{*}{\multicolumn{2}{|c|}{$\begin{array}{l}\text { Hombres } \\
\text { Mujeres }\end{array}$}} & 14.600 \\
\hline & & & & & & & 19.550 \\
\hline & & & & & \multicolumn{3}{|c|}{ * Serv. Aux.+Admin.Púb./Def. } \\
\hline & & & & & \multicolumn{3}{|c|}{ Fuente: SEPE. } \\
\hline
\end{tabular}


Las AAPP tiene en Gipuzkoa un aumento notable de sus efectivos entre 1995 y 2010, siendo 2011 y 2012 los primeros años de inversión de esta tendencia. El empleo es asalariado en su totalidad y bastante cercanos al tiempo completo como norma dominante.

El VAB del sector se ha doblado entre 1995 y 2011, estando la productividad horaria por debajo de la media provincial y la remuneración horaria por encima de la misma. Esta última está estancada desde 2008 en términos nominales. Los CLU han bajado ligeramente en el periodo.

Las jornadas anuales medias descienden entre 1995 y 2007, a partir de cuándo se estancan y dejan de disminuir.

A nuestro entender, sí procede una política de RTT porque la productividad del sector es alta y los CLU ligeramente decrecientes, el volumen de empleo se mantiene estable y existe poca parcialidad en el mismo. Igualmente, las jornadas anuales son estables, al tiempo que se da un dinamismo en las contrataciones en 2014.

Tabla 14

Indicadores sociolaborales.

Educación

\begin{tabular}{|c|c|c|c|c|c|c|c|}
\hline Datos de síntesis & 1995 & 2007 & 2008 & 2009 & 2010 & 2011 & 2012 \\
\hline Personas ocupadas & 14.938 & 19.575 & 20.338 & 21.487 & 21.779 & 22.214 & 21.989 \\
\hline Personas asalariadas & 13.884 & 18.701 & 19.433 & 20.563 & 20.848 & 21.265 & 21.040 \\
\hline$\%$ asalariadas/empleadas del sector & $93 \%$ & $96 \%$ & $96 \%$ & $96 \%$ & $96 \%$ & $96 \%$ & $96 \%$ \\
\hline Puestos de trabajo asalariado & 14.600 & 19.664 & 20.434 & 21.622 & 21.922 & 22.360 & 22.124 \\
\hline T. completitud asalariadas $\left(^{*}\right)$ & $88,3 \%$ & $88,3 \%$ & $88,4 \%$ & $88,9 \%$ & $89,6 \%$ & $89,6 \%$ & $89,6 \%$ \\
\hline VAB sectorial (miles $€$ ) & 388.681 & 860.975 & 926.107 & 1.017.978 & 1.061 .264 & 1.059 .351 & 1.028 .927 \\
\hline Productividad horaria población ocupada & $18,1 €$ & $30,8 €$ & $31,8 €$ & $32,9 €$ & $33,4 €$ & $32,6 €$ & $32,0 €$ \\
\hline Remuneración por hora asalariada & $18,9 €$ & $29,6 €$ & $30,3 €$ & $30,8 €$ & $32,7 €$ & $32,1 €$ & $30,6 €$ \\
\hline Costes laborales unitarios reales & $104 \%$ & $96 \%$ & $95 \%$ & $94 \%$ & $98 \%$ & $98 \%$ & $96 \%$ \\
\hline Horas anuales asalariados t. completo & 1.469 & 1.426 & 1.422 & 1.420 & 1.430 & 1.430 & 1.429 \\
\hline Horas anuales por asalariado reales & 1.365 & 1.324 & 1.322 & 1.327 & 1.348 & 1.347 & 1.347 \\
\hline \multicolumn{5}{|c|}{${ }^{*}$ T. completitud $=$ Puestos E.T.C./Puestos total. } & \multicolumn{3}{|c|}{ Contratos iniciales 2014} \\
\hline \multirow{2}{*}{\multicolumn{5}{|c|}{ Fuente: EUSTAT }} & Hombres & & 2.759 \\
\hline & & & & & Mujeres & & 8.185 \\
\hline
\end{tabular}

Fuente: SEPE. 
La Educación es un sector muy importante de la economía gipuzkoana y el volumen de empleo aumenta notablemente entre 1995 y 2011, siendo 2012 un año dónde el empleo recula ligeramente.

La parte de asalariadas aumenta y podemos observar que la tasa de completitud está por debajo de la media provincial.

El VAB del sector aumenta notablemente durante este periodo, estando la productividad y la remuneración horaria estancada en términos nominales -lo que muestra un retroceso real- Los CLU son altos aunque decrecientes entre 1995 y 2007, permaneciendo relativamente estables en los ańos siguientes.

La jornada anual media es muy baja y el volumen de contrataciones en 2014 no es demasiado alto en relación al conjunto de empleos.

Los altos CLU y las bajas jornadas anuales medias, así como la parcialidad por encima del conjunto de la provincia nos muestra dificultades para una política de RTT.

Tabla 15

Indicadores sociolaborales.

Actividades sanitarias

\begin{tabular}{|c|c|c|c|c|c|c|c|}
\hline Datos de síntesis & 1995 & 2007 & 2008 & 2009 & 2010 & 2011 & 2012 \\
\hline Personas ocupadas & 10.393 & 12.887 & 13.677 & 14.201 & 14.396 & 14.540 & 14.471 \\
\hline Personas asalariadas & 10.253 & 12.101 & 12.775 & 13.352 & 13.540 & 13.676 & 13.604 \\
\hline$\%$ asalariadas/empleadas del sector & $99 \%$ & $94 \%$ & $93 \%$ & $94 \%$ & $94 \%$ & $94 \%$ & $94 \%$ \\
\hline Puestos de trabajo asalariado & 15.609 & 17.865 & 18.276 & 18.458 & 18.760 & 18.521 & 18.336 \\
\hline T. completitud asalariadas $\left(^{*}\right)$ & $98,0 \%$ & $98,0 \%$ & $97,9 \%$ & $97,9 \%$ & $97,9 \%$ & $97,9 \%$ & $97,9 \%$ \\
\hline VAB sectorial (miles $€$ ) & 465.195 & 950.549 & 1.027 .553 & 1.098 .501 & 1.138 .109 & 1.153 .430 & 1.137 .504 \\
\hline Productividad horaria población ocupada & $25,8 €$ & $43,8 €$ & $44,6 €$ & $46,3 €$ & $47,7 €$ & $49,6 €$ & $49,1 €$ \\
\hline Remuneración por hora asalariada & $15,0 €$ & $26,1 €$ & $26,6 €$ & $27,7 €$ & $29,4 €$ & $29,7 €$ & $28,8 €$ \\
\hline Costes laborales unitarios reales & $58 \%$ & $60 \%$ & $60 \%$ & $60 \%$ & $62 \%$ & $60 \%$ & $59 \%$ \\
\hline Horas anuales asalariados t. completo & 1.692 & 1.643 & 1.643 & 1.638 & 1.636 & 1.602 & 1.602 \\
\hline Horas anuales por asalariado reales & 1.671 & 1.629 & 1.631 & 1.620 & 1.608 & 1.574 & 1.574 \\
\hline
\end{tabular}

* T. completitud = Puestos E.T.C./Puestos total.

Fuente: EUSTAT.

\begin{tabular}{lr}
\multicolumn{2}{c}{ Contratos iniciales $2014\left(^{*}\right)$} \\
\hline Hombres & 5.140 \\
Mujeres & 19.198 \\
\hline
\end{tabular}

* Activ. Sanit. + Serv. Soc.

Fuente: SEPE 
A diferencia de otros sectores, las actividades sanitarias aumentan el número de personas empleadas en mayor medida en los últimos ańos. La parte de asalariadas sobre el total de personas ocupadas disminuye en el periodo estudiado, siendo en su mayoría empleadas a tiempo completo.

El VAB aumenta también en el periodo, estancándose en términos nominales entre 2010 y 2012. La productividad y la remuneración horaria están por encima de la media provincial. Mientras la primera sigue aumentando también en los últimos años observados, la remuneración por hora asalariada se estanca y, en términos reales, es decreciente en este periodo, dónde el ajuste en vez de realizarse mediante el volumen de empleo se hace mediante las remuneraciones. Esta composición macroeconómica del sector nos muestra, por tanto, unos CLU bajos y estables a lo largo de todo el periodo, bajando en los últimos dos ańos observados.

Las jornadas anuales medias se reducen a lo largo de todo el periodo.

Los bajos CLU y el aguante del empleo en el sector pueden hacer que las políticas de RTT sean viables, más y cuándo se da un estancamiento de los salarios reales $y$, por tanto, puede parecer justificada esta otra forma de adaptación de empleo y necesidades del sector.

Tabla 16

Indicadores sociolaborales. Servicios sociales

\begin{tabular}{|c|c|c|c|c|c|c|c|}
\hline Datos de síntesis & 1995 & 2007 & 2008 & 2009 & 2010 & 2011 & 2012 \\
\hline Personas ocupadas & 5.612 & 7.032 & 7.315 & 7.727 & 8.067 & 7.983 & 8.227 \\
\hline Personas asalariadas & 5.573 & 6.954 & 7.264 & 7.673 & 8.010 & 7.926 & 8.169 \\
\hline$\%$ asalariadas/empleadas del sector & $99 \%$ & $99 \%$ & $99 \%$ & $99 \%$ & $99 \%$ & $99 \%$ & $99 \%$ \\
\hline Puestos de trabajo asalariado & 5.724 & 7.143 & 7.462 & 7.882 & 8.228 & 8.142 & 8.391 \\
\hline T. completitud asalariadas $\left(^{*}\right)$ & $96,0 \%$ & $95,8 \%$ & $95,3 \%$ & $95,1 \%$ & $95,1 \%$ & $95,0 \%$ & $95,0 \%$ \\
\hline VAB sectorial (miles $€$ ) & 73.938 & 154.216 & 168.207 & 183.468 & 189.546 & 206.578 & 194.906 \\
\hline Productividad horaria población ocupada & $7,8 €$ & $13,2 €$ & $13,9 €$ & $14,5 €$ & $14,3 €$ & $15,8 €$ & $14,4 €$ \\
\hline Remuneración por hora asalariada & $4,7 €$ & $7,5 €$ & $7,7 €$ & $7,9 €$ & $11,2 €$ & $11,3 €$ & $11,3 €$ \\
\hline Costes laborales unitarios reales & $61 \%$ & $57 \%$ & $55 \%$ & $55 \%$ & $78 \%$ & $72 \%$ & $78 \%$ \\
\hline Horas anuales asalariados t. completo & 1.663 & 1.642 & 1.647 & 1.635 & 1.637 & 1.639 & 1.639 \\
\hline Horas anuales por asalariado reales & 1.640 & 1.616 & 1.612 & 1.598 & 1.599 & 1.600 & 1.600 \\
\hline \multicolumn{5}{|c|}{${ }^{*}$ T. completitud = Puestos E.T.C./Puestos total. } & \multicolumn{3}{|c|}{ Contratos iniciales $2014\left(^{*}\right)$} \\
\hline \multirow{2}{*}{\multicolumn{5}{|c|}{ Fuente: EUSTAT. }} & \multicolumn{2}{|l|}{ Hombres } & 5.140 \\
\hline & & & & & \multicolumn{2}{|l|}{ Mujeres } & 19.198 \\
\hline
\end{tabular}

* Activ. Sanit. + Serv. Soc.

Fuente: SEPE. 
$\mathrm{Al}$ igual que en el anterior sector, el volumen de empleo en los Servicios sociales es creciente a lo largo de todo el periodo, incluidos los últimos años. Las asalariadas son casi en exclusiva la modalidad de ocupación y la tasa de completitud está por encima de la media provincial.

El VAB del sector es creciente en todo el periodo, a excepción de 2012 donde se puede notar un ligero descenso en términos nominales. La productividad y la remuneración horarias son muy bajas, siendo así mismo los CLU, tras descensos anteriores, crecientes en los últimos ańos observados - fruto del estancamiento de la productividad y el aumento de las remuneraciones-.

Las jornadas medias anuales han descendido ligeramente en todo el periodo, estando cerca de la media provincial.

Las bajas productividades y los aumentos en las CLU los últimos años observados no invitan a pensar que las políticas de RTT sean muy viables en este sector.

Tabla 17

Indicadores sociolaborales. Actividades de los hogares

\begin{tabular}{lccccccc}
\hline \multicolumn{1}{c}{ Datos de síntesis } & 1995 & 2007 & 2008 & 2009 & 2010 & 2011 & 2012 \\
\hline Personas ocupadas & 7.408 & 11.829 & 12.303 & 12.794 & 12.905 & 14.042 & 13.635 \\
Personas asalariadas & 7.408 & 11.829 & 12.303 & 12.794 & 12.905 & 14.042 & 13.635 \\
\% asalariadas/empleadas del sector & $100 \%$ & $100 \%$ & $100 \%$ & $100 \%$ & $100 \%$ & $100 \%$ & $100 \%$ \\
Puestos de trabajo asalariado & 10.583 & 16.899 & 17.576 & 18.278 & 18.436 & 20.060 & 19.478 \\
T. completitud asalariadas (*) & $38,9 \%$ & $38,9 \%$ & $38,9 \%$ & $38,5 \%$ & $39,6 \%$ & $39,6 \%$ & $39,6 \%$ \\
\hline \multicolumn{1}{c}{ VAB sectorial (miles $€)$} & 59.011 & 120.097 & 125.501 & 135.741 & 135.848 & 152.888 & 154.570 \\
\hline Productividad horaria población ocupada & $6,5 €$ & $8,6 €$ & $8,6 €$ & $9,0 €$ & $8,9 €$ & $10,7 €$ & $11,1 €$ \\
Remuneración por hora asalariada & $6,6 €$ & $8,6 €$ & $8,6 €$ & $8,4 €$ & $8,9 €$ & $10,3 €$ & $11,0 €$ \\
Costes laborales unitarios reales & $102 \%$ & $100 \%$ & $100 \%$ & $93 \%$ & $100 \%$ & $97 \%$ & $99 \%$ \\
\hline
\end{tabular}

\begin{tabular}{llllllll}
\hline Horas anuales asalariados t. completo & 2.203 & 2.123 & 2.124 & 2.134 & 2.100 & 1.800 & 1.827 \\
Horas anuales por asalariado reales & 1.225 & 1.181 & 1.180 & 1.174 & 1.187 & 1.017 & 1.033 \\
\hline
\end{tabular}

* T. completitud = Puestos E.T.C./Puestos total.

Fuente: EUSTAT.

\begin{tabular}{lr}
\multicolumn{2}{c}{ Contratos iniciales 2014} \\
\hline Hombres & 449 \\
Mujeres & 4.859 \\
\hline
\end{tabular}

Fuente: SEPE. 
El volumen de empleo, $100 \%$ asalariado, es creciente en todo el periodo, incluido los años de crisis a excepción del 2012. El empleo a tiempo parcial es la norma del sector que, además de por las tasas de completitud, puede observarse por la fuerte diferencia entre la jornada media anual de los asalariadas a tiempo completo y la jornada anual media real o efectiva.

El VAB crece en todo el periodo pero no deja de ser bajo para el volumen de empleo, lo cual deja muestra unas prodictividade sy remuneraciones horarias bajas y unos CLU altos.

Las jornadas medias anuales se han reducido en todo el periodo.

No es viable hacer políticas de RTT en un panorama con tarta parcialidad en el empleo y productividades tan bajas, así como jornadas anuales medias efectivas que distan tanto de las que muestran las personas asalariadas a tiempos completo.

\section{Agrupando sectores según el grado de viabilidad de políticas de RTT}

Para terminar presentamos los sectores agrupados según se den mejores condiciones macroeconómicas para una política de RTT que, si bien es posible en empresas y entornos de todas las ramas de actividad, muestra situaciones sectoriales de carácter estructural y coyuntural, las cuáles se han tratado de sintetizar en los indicadores anteriormente expuestos. La RTT es, además de un bien en sí misma por liberar tiempo de vida de las personas trabajadoras para otras actividades, una opción para generar nuevos empleos. Según Reichmann y Recio (1997: 61-62), la RTT será un punto de partida para la creación de nuevos empleos en función de pautas técnicas y organizativas de cada actividad, y mayormente en actividades que requieren pocos medios de producción. Igualmente, Alonso y Pérez (1996: 77) apuntan que la RTT será más generadora de empleos en aquellas actividades medidas por el tiempo de presencia. En estas actividades la intensificación de las tareas es imposible, dándose una relación no alterable entre horas de trabajo y productividad, no pudiendo la RTT contrarrestarse con una intensificación de los ritmos de trabajo. Igualmente, nos recuerdan (95) que la creación de empleo vía la RTT está ligada al contexto socioeconómico, consideración que nos ha llevado a señalar, como más viables para una política de RTT, aquellos sectores en los que los VAB globales son crecientes y en los que existe una dinámica de creación de nuevos empleos, previa a la RTT que se propone (en nuestro caso, 2014).

Además, el factor clave está en la evolución de los CLU, que muestra la relación entre productividad y remuneración horaria de cada puesto asalariado. A nivel agregado, consideramos más viable la introducción de la RTT en la agenda 
de la negociación colectiva tanto para aquellos sectores en los que los CLU son menores como en aquellos en los que están evolucionando a la baja, tanto en el ciclo largo desde 1995 como en los años desde el inicio de la crisis financiera de las economías europeas.

Tabla 18

Costes laborales unitarios en Gipuzkoa. Por sectores. Evolución 1995-2012 y 2007-2012

\begin{tabular}{lrrr}
\hline \multicolumn{1}{c}{ Costes laborales unitarios gipuzkoa } & 2012 & var $95-12$ & var $07-12$ \\
\hline 1. Agricultura, ganadería y pesca & $89,0 \%$ & $-30,90 \%$ & $-6,42 \%$ \\
10. Metalurgia y productos metálicos & $76,3 \%$ & $12,88 \%$ & $38,47 \%$ \\
13. Maquinaria y equipo & $60,0 \%$ & $-14,88 \%$ & $-8,55 \%$ \\
14. Material de transporte & $50,6 \%$ & $-28,37 \%$ & $-2,16 \%$ \\
18. Construcción & $91,3 \%$ & $-3,37 \%$ & $7,98 \%$ \\
19. Comercio; reparación de vehículos & $67,7 \%$ & $-4,37 \%$ & $1,83 \%$ \\
20. Transporte y almacenamiento & $78,2 \%$ & $7,11 \%$ & $1,93 \%$ \\
21. Hostelería & $75,4 \%$ & $16,78 \%$ & $15,71 \%$ \\
25. Actividades financieras y seguros & $28,3 \%$ & $-5,40 \%$ & $16,69 \%$ \\
27. Consultorías y actividades técnicas & $66,7 \%$ & $82,80 \%$ & $8,27 \%$ \\
30. Servicios auxiliares & $80,1 \%$ & $13,35 \%$ & $-8,40 \%$ \\
31. Administración pública y defensa & $85,6 \%$ & $-4,36 \%$ & $-0,34 \%$ \\
32. Educación & $95,6 \%$ & $-8,38 \%$ & $-0,61 \%$ \\
33. Actividades sanitarias & $58,6 \%$ & $1,13 \%$ & $-1,74 \%$ \\
34. Actividades de servicios sociales & $78,1 \%$ & $28,27 \%$ & $36,97 \%$ \\
37. Actividades de los hogares & $98,5 \%$ & $-3,63 \%$ & $-1,48 \%$ \\
\hline Gipuzkoa & $62,4 \%$ & $-3,13 \%$ & $2,64 \%$ \\
\hline
\end{tabular}

Fuente: Castrillón et al. (2016b).

Más allá de estas consideraciones generales no debemos olvidar que, siendo la siguiente categorización una construcción según su viabilidad sectorial agregada, las políticas de RTT generalizada son capaces de repartir los empleos y generar marcos de vida laboral menos duales entre quienes tienen un trabajo remunerado y quiénes no. Esta capacidad se amplía en el caso de que esta RTT sea además sustancial, equitativa y redistributiva (De la Fuente y Zubiri, 2016a). Además, la RTT interpela sobre todo a nuestras sociedades sobre la cuestión de que prioridades se establecen en la negociación colectiva y, sobre todo, de los frentes de movilización que se impulsan - $\mathrm{O}$ no- desde las clases trabajadoras y sus organizaciones representativas. A esta cuestión casi fundacional del movimiento obrero, se le suma la importancia de una RTT para un reparto del tra- 
bajo de cuidados en los hogares, reduciendose la concentración y mayor intensidad de las mismas en las mujeres, al tener fruto de estas políticas todos y todas más tiempo libre del empleo.

Aún así, las condiciones macroeconómicas y la evolución de los indicadores laborales sectoriales marcan las bases materiales de las mencionadas negociaciones y conflictos y, por tanto, nos permiten establecer tres zonas o grupos de sectores (en paréntesis, n. ${ }^{\circ}$ de empleos asalariados en 2012) según la viabilidad de las políticas de RTT, tal y como se ha argumentado esquemáticamente a la luz de cada una de las tablas presentadas en esta sección.

-Zona 1: Sectores con mayor viabilidad de políticas de RTT $=60.599$ asalariadas en 2012:

- Maquinaría y equipo (13.609).

- Transporte y almacenamiento (9.436).

- Actividades financieras y seguros (5.825).

- Administración pública y defensa (18.125).

- Actividades sanitarias (13.604).

-Zona 2: Sectores con viabilidad media para una política de RTT = 81.986 asalariadas en 2012:

- Material de transporte (5.361).

- Construcción (15.186).

- Comercio y reparación de vehículos (34.706).

- Hostelería (14.399).

- Servicios auxiliares (12.334).

-Zona 3: Sectores con peores condiciones para una política de RTT = 79.404 asalariadas en 2012:

- Agricultura, ganadería y pesca (2.088).

- Metalurgia y productos metálicos (26.024).

- Consultorías y actividades técnicas (8.448).

- Educación (21.040).

- Servicios sociales (8.169).

- Actividades de los hogares (13.635).

Sin haberse hecho una diferenciación interna a cada uno de estos sectores - por tamaños de empresas, margen de excedente, función social y ambiental saludable o nociva...-, no se debe olvidar que hay múltiples factores - macroeconómicos, legales, de relación de fuerza, de dinámica y control de las empresas...- que influyen en la viabilidad agregada de la RTT que hemos expuesto y desarrollado con más detalle en Castrillón et al. (2016d). El ejercicio aquí realizado es fruto de una panorámica general de cada rama de actividad la- 
boral en la economía gipuzkoana, no pudiendo abarcar ni cuestiones de coyuntura más recientes (hasta 2016) ni aspectos de segmentación interna de cada sector, siendo estos últimos cruciales en el establecimiento de medidas de obligado cumplimiento por las empresas. Por otro lado, la financiación de las medidas de RTT que se propondrán en Castrillón et al. (2016d) es uno de los factores que más suele frenar el discurso hegemónico en los debates sobre políticas laborales y sus posibilidades de avance social. La resolución de esta cuestión crucial del "qquién paga?» no debe frenar el debate sobre la importancia de revertir la distribución funcional de la renta que ha evolucionado en contra de las personas asalariadas durante las últimas décadas.

\section{Conclusiones}

Teniendo en cuenta la evolución de los indicadores laborales por sectores, consideramos que en algunos son macroeconómicamente más viables las políticas de Reducción del Tiempo de Trabajo. Esto es así por razones técnicas y de viabilidad más clara, así como políticas — y, por tanto, de mayor calado- sobre un reparto más justo de los excedentes productivos. La mecánica que nos lleva a considerar más o menos viables la RTT a escala sectorial ha sido presentada en la introduccción, siendo justificación y desenvoolvimiento técnico más desarrollado en De la Fuente y Zubiri (2016a) y Castrillón et al. (2016d). Dicho esto, falta apuntar que nuestra presente exposición nos ha llevado a considerar que los sectores que en Gipuzkoa presentan unas mejores condiciones para la RTT son son los siguientes ( $\mathrm{n} .^{\circ}$ de ocupados total):

- Maquinaría y equipo (13.609): La caída continuada de los CLU desde hace dos décadas se intensifica desde el 2010, lo que se suma al dinamismo en las nuevas contrataciones y el estancamiento de las jornadas en el periodo reciente.

- Transporte y almacenamiento (9.436): Con unos VAB crecientes en el sector, los CLU tienen una caída importante en 2011 y 2012, además de un ritmo dinámico de contratación en 2014 que hacen factible la RTT.

- Actividades financieras y seguros (5.825): Siendo el sector de pproductividades más altas y VAB estables desde el inicio de la crisis, los CLU se mantienen bajos lo que, a pesar de la escasa contratación, da pie a una RTT viable para todo el sector.

— Administración pública y defensa (18.125): Siendo un sector con una productividad alta y CLU ligeramente decrecientes, el estancamiento de la jornada desde el inicio de la crisis y el dinamismo en las nuevas contrataciones dan pie a una RTT generalizada en el sector. 
- Actividades sanitarias (13.604): Con unos CLU bajos y decrecientes fruto de la caída de las remuneraciones reales, el dinamismo en las contrataciones y los aumentos en el VAB sectorial muestran la viabilidad de la RTT.

Igualmente, hemos delimitado una franja de viabilidad intermedia de sectores de cara a la RTT, siendo estos:

- Material de transporte (5.361): Siendo el de menor incidencia cuantitativa de los aqui presentados, los bajos CLU y el fuerte dinamismo en las nuevas contrataciones —en relación al volumen de empleo en el sectordan muestra de la posibilidad de mayores RTT en este sector, siendo por contra la baja jornada y su fuerte caída en 2012 una muestra de que se trata de un camino ya explorado en el mismo.

- Construcción (15.186): La evolucción del empleo, la caída de la parte de asalariados y el aumento de la parcialidad muestran una vía alternativa a la RTT generalizada y equitativa que propugnamos. Aún así los altos CLU y el estancamiento de la productividad desde el 2007 dificultan esta vía.

- Comercio y reparación de vehículos (34.706): A pesar de su baja productividad, el caracter estable de los CLU y la fuerte dinámica de contratación en este sector da pie a una posibilidad de RTT, más cuándo la jornada de las asalariadas a tiempo completo se ha incrementado desde el inicio de la crisis.

- Hostelería (14.399): Tanto el incremento del volumen de ocupados como el de las jornadas de las personas asalariadas a tiempo compleo, asi como el fuerte dinamismo en las nuevas contrataciones, dan pie a una RTT en el sector, lo que se dificulta por los aumento de los CLU en los últimos años.

- Servicios auxiliares (12.334): Además de resolver el deficit de este sector en cuanto a bajos salarios - sólo superado en este plano por los servicios sociales y las actividades de los hogares-, los incrementos del volumen de negocio en los últimos años, así cómo la caída de los CLU y el dinamismo contratador, permiten apuntar a la necesidad de una RTT generalizada, lo que permitiría invertir la parcialidad en el empleo, bastante considerable en este sector.

Como hemos explicado en la introducción, esto se da por una confluencia de factores, entre los que los más destacados son:

- Que en el sector haya incrementos anuales de VAB.

— En el empleo desde 2008 no haya habido grandes caídas de efectivos.

- Haya contrataciones anuales en parte significativas respecto al volumen de empleo en el sector. 
- Las jornadas anuales de los tiempos completos o las jornadas medias reales no hayan ido bajando en los últimos años; y otros.

Con este ejercicio concluimos la defensa de nuestra tesis de que se dan en Gipuzkoa las condiciones para una reducción del tiempo de trabajo generalizada sustancial, equitativa y redistributiva (De la Fuente y Zubiri, 2016a), lo cual ha de efectuarse desde proyecciones serias de compensación de la distribución primaria de las rentas del capital y del trabajo. La escala sectorial es uno de los ámbitos de negociación en los que puede sostenerse la necesidad de este ejercicio de compensación macroeconómica, en favor de las personas asalariadas.

Por otro lado, la financiación de las medidas de RTT que se proponen en Castrillón et al. (2016d) es uno de los factores que más suele frenar el discurso hegemónico en los debates sobre políticas laborales y sus posibilidades de avance social. La resolución de esta cuestión crucial del «¿quién paga?» no debe frenar el debate sobre la importancia de revertir la distribución funcional de la renta que ha evolucionado en contra de las personas asalariadas durante las últimas décadas.

\section{Bibliografía}

Alonso, Luis Enrique (1996): ¿Trabajo para todos?: Un debate necesario. Madrid, Ediciones Encuentro.

Álvarez Peralta, Nacho, Alonso, Luis Enrique, Uxó, Jorge (2013): Fractura y crisis en Europa. Madrid, Clave intelectual, 342.

Berbel, Sara (2015): «Contratos a tiempo parcial: ¿oportunidad o trampa para las mujeres?», eldiario.es.

Castrillón, Verónica, Zendoia, Jose Mari y Zubiri, Jon Bernat (2016a): «Diagnóstico del empleo en Gipuzkoa», Lan Harremanak. Revista de Relaciones Laborales, n. ${ }^{\circ} 34$, $2016(1)$.

Castrillón, Verónica, Zendoia, Jose Mari y Zubiri, Jon Bernat (2016b): «Distribución funcional de la renta y costes laborales en Gipuzkoa: un estudio empírico para la reducción del tiempo de trabajo", Lan Harremanak. Revista de Relaciones Laborales, n. ${ }^{\circ} 34,2016$ (1).

Castrillón, Verónica, Zendoia, Jose Mari y Zubiri, Jon Bernat (2016d): «Propuestas de reducción del tiempo de trabajo en Gipuzkoa", Lan Harremanak. Revista de Relaciones Laborales, n. ${ }^{\circ}$ 34, 2016 (1).

Duran Rodríguez, José (2015): «Horas extras: el mayor robo de la historia», Diagonal (254), 2.

De la Fuente, Mikel. y Zubiri, Jon Bernat (2016): «Significado histórico y actualidad de las políticas de reducción del tiempo de trabajo» Lan Harremanak. Revista de Relaciones Laborales, n. ${ }^{\circ}$ 34, 2016 (1).

Riechman, Jorge y Recio, Albert (1997): Quien parte y reparte... El debate sobre la reducción del tiempo de trabajo, Barcelona, Icaria. 